\title{
Endoscopic ultrasound-guided fine needle aspiration of a pericardial mass
}

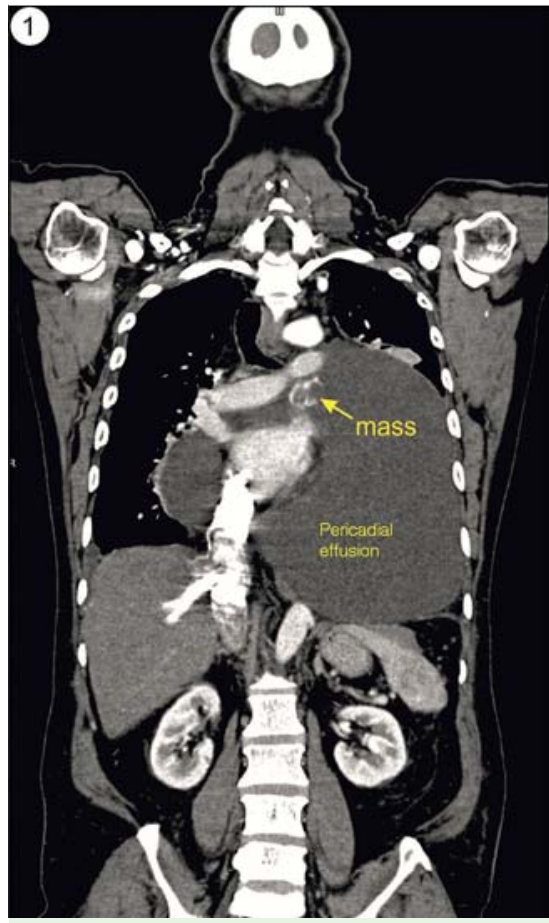

Fig. 1 Computed tomography (CT) scan of the thorax showing a well-defined heterogeneously enhancing lesion, $2.1 \times 1.8 \times 1.8 \mathrm{~cm}$ in size, attached to the posterior pericardium and a pericardial effusion.

The prevalence of primary pericardial neoplasms ranges from about $0.001 \%-$ $0.007 \%$. Primary malignant pericardial mesothelioma is extremely rare, with a reported prevalence of $0.0022 \%$ in autopsy series [1]. Although malignant mesothelioma is the most common primary malignancy of the pericardium, only approximately 350 cases of pericardial mesothelioma have been reported in the literature.

Diagnosing pericardial disease can be challenging, with an antemortem diagnosis of pericardial mesothelioma obtained in only $10 \%-20 \%$ of cases. Cross-sectional imaging is useful for diagnosis, but cytological and/or histological examinations are required to obtain a definitive diagnosis. Cytological analysis of the pericardial fluid often yields negative results; therefore, the diagnosis usually requires histologic evaluation of tissue obtained during surgery or at autopsy. In patients with metastasis, half have regional lymph node involvement; hence, as already reported,

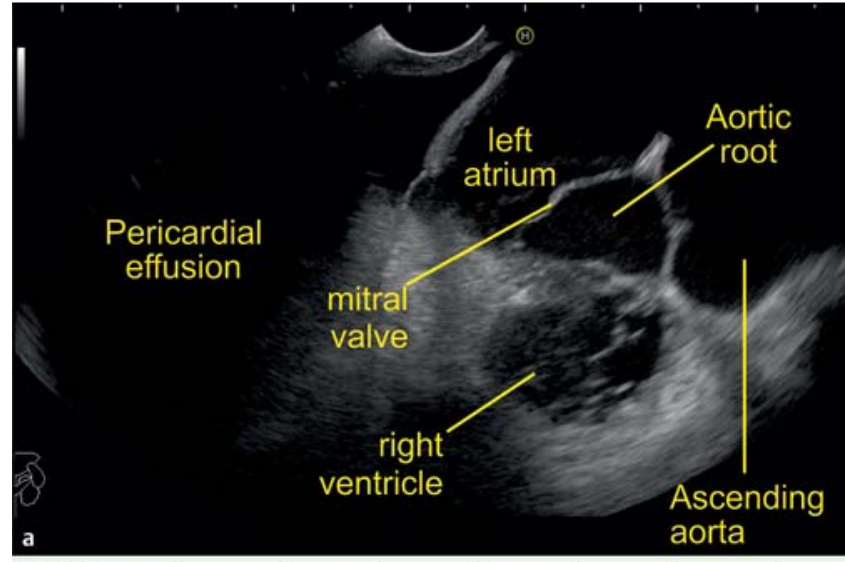

Fig. 2 Linear endoscopic ultrasound (EUS) images showing: a a pericardial effusion with normal chambers of the heart; $\mathbf{b}$ a mixed echogenic pericardial mass with a pericardial effusion; $\boldsymbol{c}$ the pericardial mass being punctured with a fine needle aspiration (FNA) needle.
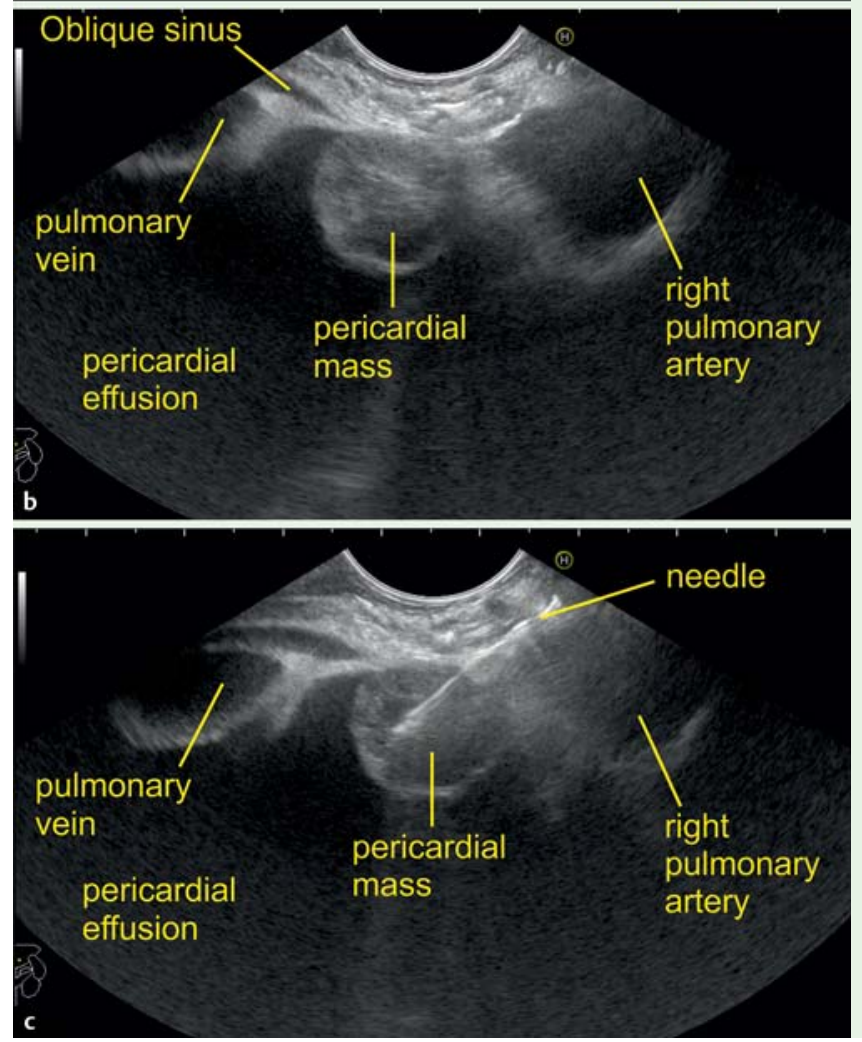

endoscopic ultrasound (EUS)/endobronchial ultrasound can be used to diagnose pericardial mesothelioma [2]. Because of the proximity of the heart to the esophagus, transesophageal EUS-guided access to the heart has been performed safely in animal models and humans [3]. There are a few case reports of EUS-guided fine needle aspiration (FNA) of atrial and pericardial tumors $[4,5]$.

A 55-year-old man presented with progressive dyspnea on exertion over the preceding 4 months. Computed tomog- raphy $(\mathrm{CT})$ of the thorax revealed a welldefined heterogeneously enhancing lesion, $2.1 \times 1.8 \times 1.8 \mathrm{~cm}$ in size, attached to the posterior pericardium and a pericardial effusion ( $\bullet$ Fig. 1). Pericardiocentesis was performed, but analyses for malignant cells and tuberculosis were negative. Given the necessity of obtaining a tissue diagnosis, an EUS-guided transesophageal FNA of the mass was considered, and was performed in the endoscopy room after the cardiologist and cardiovascular surgical teams had been alerted. Linear EUS re- 


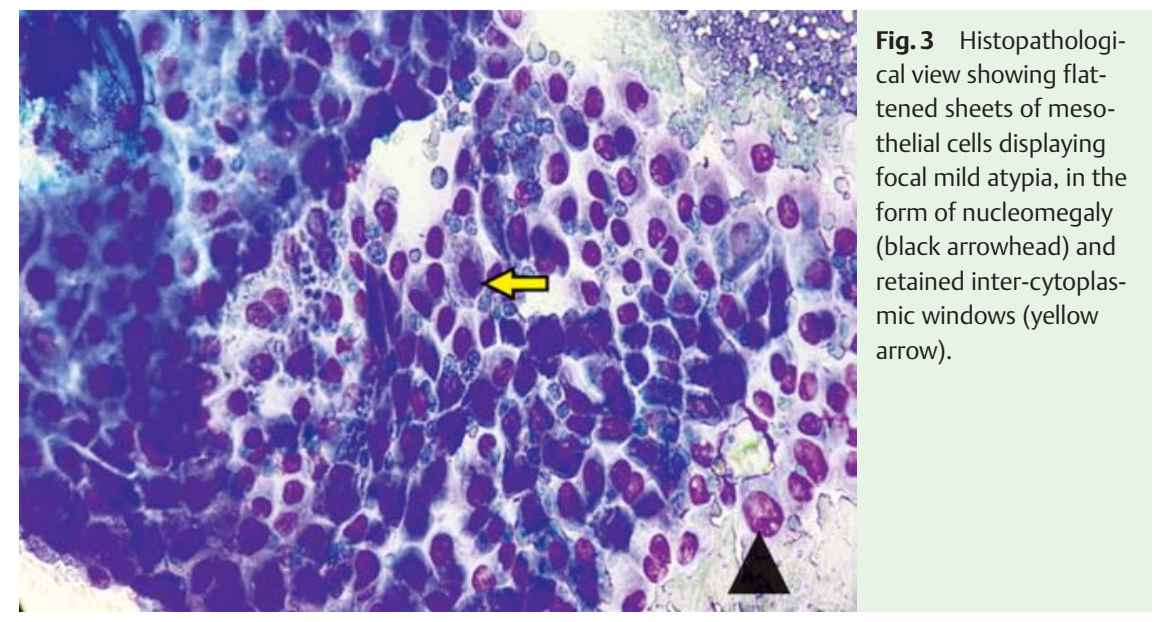

vealed a mixed echogenic pericardial mass with a pericardial effusion ( Fig. 2 a, - Fig. 2b). The lesion was punctured with a 22-gauge needle (Expect; Boston Scientific, Natick, Massachusetts, USA) with five passes made ( $\bullet$ Fig. 2 c; $\bullet$ Video 1 ). No arrhythmias or other adverse events occurred during the following 24 hours.

May-Grünwald-Giemsa (MGG) staining and immunocytochemical expression confirmed the diagnosis of pericardial mesothelioma ( $\bullet$ Fig.3). The patient subsequently died 2 weeks after diagnosis.

Endoscopy_UCTN_Code_CCL_1AF_2AC

Competing interests: None

\section{Piyush Somani, Malay Sharma, Amol Patil, Avinash Kumar}

Department of Gastroenterology, Jaswant Rai Speciality Hospital, Saket, India

\section{References}

1 Restrepo CS, Vargas D, Ocazionez D et al. Primary pericardial tumors. Radiographics 2013; 33: $1613-1630$

2 Ashinuma $H$, Shingyoji M, Yoshida $Y$ et al. Endobronchial ultrasound-guided transbronchial needle aspiration in a patient with pericardial mesothelioma. Intern Med 2015; 54: $43-48$

3 Fritscher-Ravens A, Ganbari A, Mosse CA et al. Transesophageal endoscopic ultrasoundguided access to the heart. Endoscopy 2007; 39: $385-389$

4 Romero-Castro R, Rios-Martin JJ, GallegoGarcia de Vinuesa $P$ et al. Pericardial tumor diagnosed by EUS-guided FNA (with video). Gastrointest Endosc 2009; 69: 562-563

5 Gornals JB, de la Hera $M$, de Albert $M$ et al. EUS cardiac puncture-guided right atrial tumor. Gastrointest Endosc 2015; 82: 165

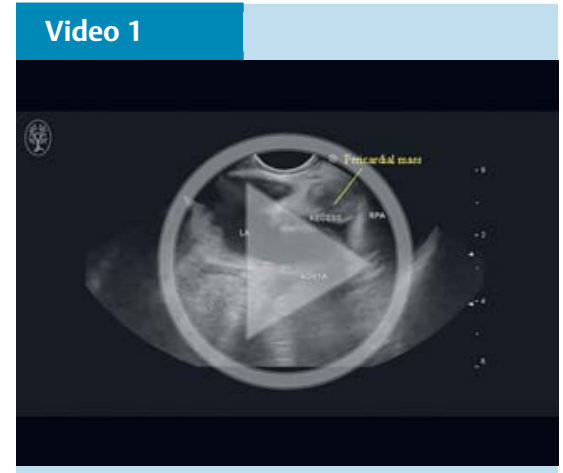

Endoscopic ultrasound (EUS) performed from the esophagus showing a pericardial effusion with a mixed echogenic pericardial mass near the right pulmonary artery. The lesion is punctured with a 22-gauge needle using smooth to-and-fro movements.

\section{Bibliography}

Dol http://dx.doi.org/

10.1055/s-0042-100202

Endoscopy 2016; 48: E45-E46

(c) Georg Thieme Verlag KG

Stuttgart · New York

ISSN 0013-726X

\section{Corresponding author} Piyush Somani, MD, DM

Department of Gastroenterology

Jaswant Rai Speciality Hospital

Saket

Meerut 250001

Uttar Pradesh

India

dr_piyushsomani@yahoo.co.in 